\title{
Problem of Thermal Generating Unit Solve Through Different Controller
}

\author{
${ }^{1}$ ASHISH DHAMANDA, ${ }^{2}$ A.K.BHARDWAJ \\ ${ }^{1,2}$ Electrical Engineering Department \\ ${ }^{1}$ Faculty of Engineering \& Technology, GKV, Haridwar, UK, INDIA \\ ${ }^{2}$ MIET Meerut, UP, INDIA \\ 1dhamanda_ashish@yahoo.co.in,2dr.akbhardwaj65@rediff.com
}

\begin{abstract}
In a thermal generating station, electricity is generated by different generating unit which are operated parallelly to fulfill the demand arises from the different consumers. In a huge and complex structure of power system, load is continuously varied so the problem of thermal generating unit (T.G.U) is to mismatch the frequency and tie line power deviations due to continuously changing of load. To solve the problem of T.G.U, different controller like; PI, PID and fuzzy controllers applied, which gives the satisfied result in normal operation but in abnormal condition, some controller takes large time to settle down the load changes problem, which is dangerous for the system. In this paper model of T.G.U has been developed and simulated in MATLAB Software. Response of the developed model has been tabulated for better comparison. The tabulated result shows that the fuzzy controller gives the good results over the other controller due to settle down the frequency and tie line power flow deviations in less time and maintain the system constancy.
\end{abstract}

Keywords: - Thermal Generating Unit (T.G.U), Frequency Deviations, Tie Line Power Deviation, PI (Proportional Plus Integral), PID (Proportional Plus Integral Plus Derivative), Fuzzy Controller.

Received: September 23, 2019. Revised: March 14, 2020. Accepted: March 26, 2020. Published: March 31, 2020.

\section{Introduction}

Electricity is globally used because it is a supremely flexible form of energy. It can be readily and efficiently transported and is easily converted to other forms of energy. The energy conversion chain follows the chemical-thermal-mechanical-electrical path. Coal is pulverized and fed into a boiler where it is mixed with forced air and combusted. The boiler is a complex structure consisting of many stages of energy extraction from the combusted fuel. The flue gases are guided through equipment that removes solid particles and sulphur (desulfurization is not shown in the figure) before being released into the atmosphere. The highly purified water in the boiler is converted into superheated steam which is passed through several turbine stages on the shaft of a turbo generator. The low-pressure low temperature steam from the outlet of the turbine is condensed into the purified water which in this closed system is pumped back into the boiler. The condensing process unfortunately needs a substantial amount of external cooling water. This water is provided from a pond at the bottom of a cooling tower. The hot water from the condenser is sprayed at the top of the tower and transfers its heat to the air that passes up the venture shaped tower. The lost water must be made up from some external source such as a local river. The energy generated at the power stations is transmitted to consumers by overhead transmission lines and underground cables.

$[1],[2],[3],[4],[5], \quad[6],[7]$, [8], [9]. 


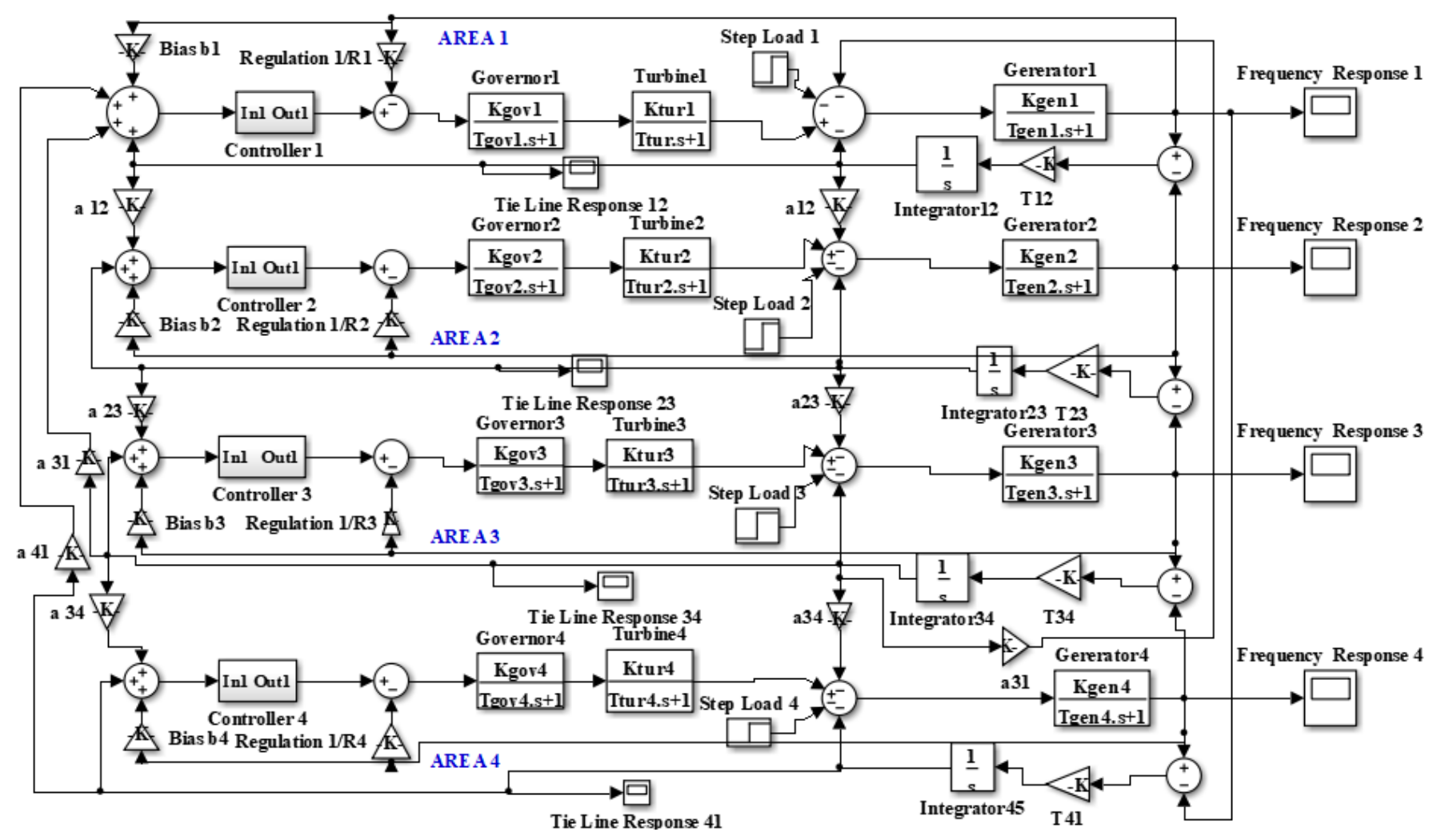

Fig. 1 Multi Area Thermal Generating Unit (TGU)

\section{Problem Formulation of AGC}

The problem of A.G.C, T.G.U systems can be mathematical express by giving the following equation; [2],[4], [5], [10], [11]

The frequency $(\Delta F(t))$ and tie-line power changes for load $\left(\Delta P_{d}\right)$ are;

$\Delta F(t)=-\frac{r K_{g e n}}{K_{g e n+r}}\left[1-e^{\left[-\frac{t}{T_{g e n}} \frac{r T g e n}{K g e n+r}\right]}\right] \Delta P_{d}$

Equation of tie line power flow in area-1 is;

$\mathrm{P}_{\mathrm{t} 11} \quad=\quad \frac{\left|V_{1}\right|\left|V_{2}\right|}{X_{t l}} \quad \sin \quad\left(\theta_{1-}\right.$

(2)

Where $\left|V_{1}\right|$ and $\left|V_{2}\right|$ are magnitude of voltage in area 1 and area 2 , respectively, $\theta_{1}$ and $\theta_{2}$ are the angles of machines of area, and $X_{t l}$ is the reactance of tie line.

Equations 1 and 2 is used to calculate the frequency and tie-line power changes corresponding to load changes for all areas of thermal generating system.
Where $\Delta P_{d}$ is increase in demand, $\mathrm{r}$ is speed governor regulation. [1], [6], [7], [8], [9], [11], [12], [13], [14].

\section{Problem Solution Methodology}

To solve the problem of AGC of thermal generating unit, different controllers like PI, PID, Fuzzy and GA controllers applied. One of the following controllers are discussed below;

\subsection{GA Controller}

It is an algorithm for solving the optimization problem that is based on natural selection process. GA presumes the solution of a problem is an individual and express by a set of parameters. Problem of TGU can be solve by calculating the GA parameters like; fitness function, population size, selection, mutation, cross over, bound limit etc. GA parameter are listed on Table 1 , 
Table 1 GA Parameters

\begin{tabular}{|c|c|}
\hline Parameter & Multi Area System \\
\hline Fitness Function & $@$ dha_ash \\
\hline Variables & 18 \\
\hline Population Size & 20 \\
\hline Selection & Stochastic Uniform \\
\hline Mutation & Constraint Dependent \\
\hline Cross Over & Scattered \\
\hline Bound Limit & Upper [0] and Lower [-5] \\
\hline
\end{tabular}

\section{Result}

This paper identified the problem of TGU of multi area system due to sudden load changes and solve by different controllers like PI, PID, Fuzzy and GA by reducing the settling time of frequency and tie-line power changes. The comparative response of multi area system has been obtained for frequency and tie-line power changes by MATLAB Simulink software given below and results are tabulated in Table 2 ,

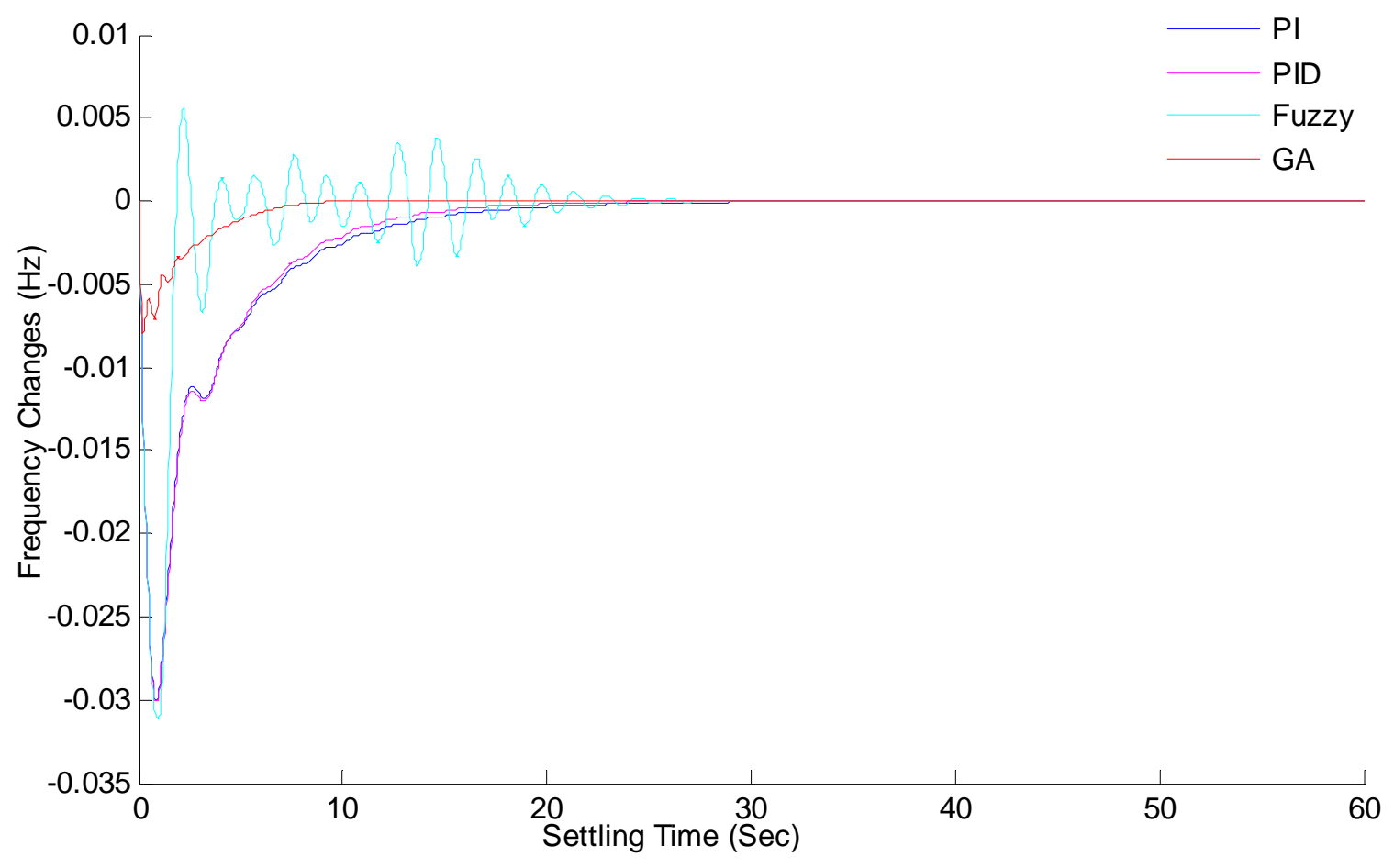

Fig. 2 Comparative response of frequency changes in Multi area system 


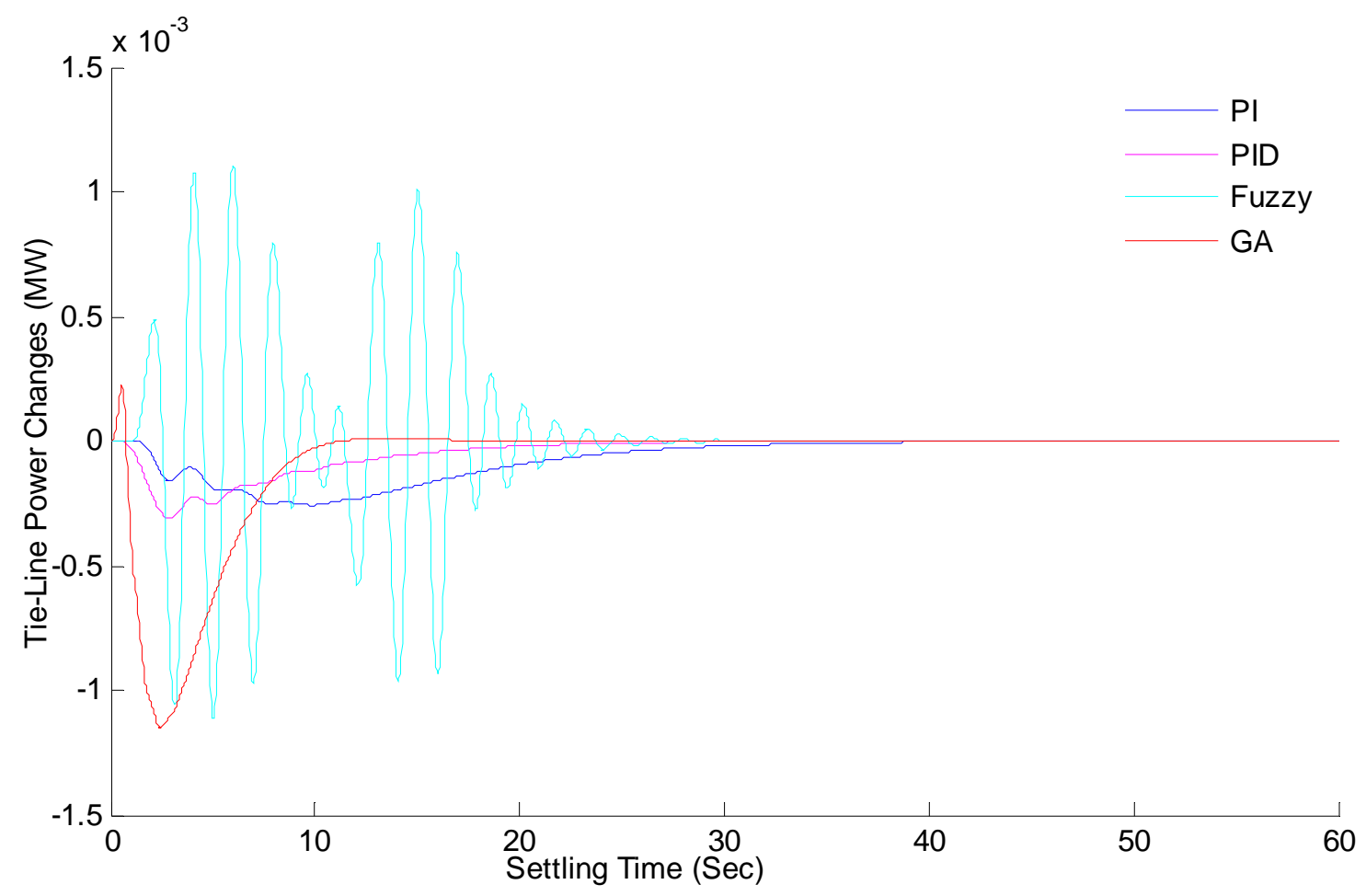

Fig. 3 Comparative response of tie-line power changes in multi area system

Table 2 Comparative Results of Frequency and Tie-Line change of TGU

\begin{tabular}{|c|c|c|c|c|c|c|c|c|}
\hline & \multicolumn{3}{|c|}{ Settling Time (Sec) of Frequency Changes } \\
in Multi Area System & \multicolumn{3}{c|}{ Settling Time (Sec) of Tie-Line Change } \\
in Multi Area System \\
\hline Controllers & $\begin{array}{c}\text { Area 1 } \\
\text { (Sec) }\end{array}$ & $\begin{array}{c}\text { Area 2 } \\
\text { (Sec) }\end{array}$ & $\begin{array}{c}\text { Area 3 } \\
\text { (Sec) }\end{array}$ & $\begin{array}{c}\text { Area 4 } \\
\text { (Sec) }\end{array}$ & $\begin{array}{c}\text { Area 1- } \\
\text { Area2 } \\
\text { (Sec) }\end{array}$ & $\begin{array}{c}\text { Area 2- } \\
\text { Area3 } \\
\text { (Sec) }\end{array}$ & $\begin{array}{c}\text { Area 3- } \\
\text { Area4 } \\
\text { (Sec) }\end{array}$ & $\begin{array}{c}\text { Area 4- } \\
\text { Area1 } \\
\text { (Sec) }\end{array}$ \\
\hline PI & 30 & 29 & 29 & 30 & 35 & 33 & 36 & 37 \\
\hline PID & 28 & 28 & 27 & 29 & 31 & 30 & 30 & 32 \\
\hline Fuzzy & 25 & 24 & 25 & 24 & 32 & 28 & 30 & 27 \\
\hline GA & 11 & 12 & 12 & 11 & 18 & 15 & 17 & 16 \\
\hline
\end{tabular}




\section{Conclusion}

Due to regularly variation of load, increase the problem to maintain the frequency and tie-line power changes. To solve the problem, a multi area TGU (thermal generating unit) system has been taken into consideration by using PI, PID, Fuzzy and GA controller. The comparative result obtained from different controllers has been listed in Table 2, which shows that the GA controller gives the better result by improving the performance of the system by taking less time to settle down the variation and maintain the system operation of load changing. So, it can be concluded that the GA controller gives dynamic performance with better result.

Appendix:

Multi Area TGU Systems Parameter are given below:

$\mathrm{F}=60 \mathrm{~Hz} ; \mathrm{R}_{1}=\mathrm{R}_{2}=\mathrm{R}_{3}=\mathrm{R}_{4}=\mathrm{R}_{5}=\mathrm{R}_{6}=2.4 \mathrm{~Hz} /$ p.uMW; $\mathrm{T}_{\text {govl }}=$ $\mathrm{T}_{\text {gov } 2}=\mathrm{T}_{\text {gov } 3}=\mathrm{T}_{\text {gov } 4}=\mathrm{T}_{\text {gov } 5}=\mathrm{T}_{\text {gov }}=0.08 \mathrm{Sec} ; \mathrm{T}_{\text {gen1 }}=\mathrm{T}_{\text {gen } 2}=\mathrm{T}_{\text {gen } 3}$ $=\mathrm{T}_{\text {gen }}=\mathrm{T}_{\text {gen } 5}=\mathrm{T}_{\text {gen } 6}=20 \mathrm{Sec} ;$ Ttur $_{1}=\mathrm{Ttur}_{2}=\mathrm{Ttur}_{3}=\mathrm{Ttur}_{4}=$ Ttur ${ }_{5}=$ Ttur $_{6}=0.3 \mathrm{Sec} ; \mathrm{A}_{12}=\mathrm{A}_{23}=\mathrm{A}_{34}=\mathrm{A}_{45}=\mathrm{A}_{56}=\mathrm{A}_{61}=1 ; \mathrm{h}_{1}=\mathrm{h}_{2}=\mathrm{h}_{3}$ $=\mathrm{h}_{4}=\mathrm{h}_{5}=\mathrm{h}_{6}=5 \mathrm{MWS} / \mathrm{MVA} ; \mathrm{p}_{\mathrm{r} 1}=\mathrm{p}_{\mathrm{r} 2}=\mathrm{p}_{\mathrm{r} 3}=\mathrm{p}_{\mathrm{r} 4}=\mathrm{p}_{\mathrm{r} 5}=\mathrm{p}_{\mathrm{r} 6}=2000 \mathrm{M}$ $\mathrm{W} ; \mathrm{K}_{\text {gen1 } 1}=\mathrm{K}_{\text {gen } 2}=\mathrm{K}_{\text {gen } 3}=\mathrm{K}_{\text {gen } 4}=\mathrm{K}_{\text {gen } 5}=\mathrm{K}_{\text {gen } 6}=120 \mathrm{~Hz} /$ puMW $; \mathrm{K}_{\mathrm{govl}}=\mathrm{K}_{\mathrm{gov} 2}=\mathrm{K}_{\mathrm{gov} 3}=\mathrm{K}_{\mathrm{gov} 4}=\mathrm{K}_{\mathrm{gov} 5}=\mathrm{K}_{\mathrm{gov} 6}=1 ; \mathrm{K}_{\mathrm{turl}}=\mathrm{K}_{\mathrm{tur} 2}=\mathrm{K}_{\mathrm{t}}$ ${ }_{\text {ur } 3}=\mathrm{K}_{\text {tur }}=\mathrm{K}_{\text {turs }=} \mathrm{K}_{\text {tur6 }}=1 ; \mathrm{d}_{1234}=8.33 * 10$ p.uMW/hz.; $\mathrm{b}_{123456}=$ 0.425 p.uMW $/ \mathrm{Hz} ; \Delta \mathrm{P}_{\mathrm{D} 123456}=0.01$ p.u; $\mathrm{T}_{12}=\mathrm{T}_{23}=\mathrm{T}_{34}=\mathrm{T}_{45}=\mathrm{T}$ ${ }_{56}=\mathrm{T}_{61}=0.0867 \mathrm{MW} / \mathrm{Rad} ; \mathrm{P}_{\text {tie } \max }=200 \mathrm{MW}$.

\section{References:}

[1] Chaturvedi Ratnesh and Dwivedi Bharti, 'Fuzzy and PI Controller Based Load Frequency Control of Thermal-Hydro Power System'. International Journal of Innovative Science, Engineering \& Technology, Vol. 1 Issue 3, May 2014.

[2] D. P. Kothari, Nagrath, Modern Power System Analysis, Tata McGraw Hill, Third Edition 2003.

[3] Elgerd O. I, Electric Energy System Theory; an Introduction, McGraw Hill 1971.

[4] Gabano J.D., Poinot T. and Kanoun H., 'Identification of a Thermal System Using Continuous Linear Parameter Varying Fractional
Modelling'. IET Control Theory Appl, 2011, Vol. 5, issue 7.

[5] Hassen S. Z. Sayed and Jahmeerbacus M. I., 'Optimal Frequency Regulation of a Two-area Power System'. IEEE 978-1-4673-4569-9/13/\$31.00@2013.

[6] Park Min-Su and Chun Yeong-Han, 'Tuning of Generating Unit Controller for the Generators with Governor'. IEEE T\&D Asia 2009.

[7] Pan C. T. and Liaw C. M., 'An Adaptive Controller for Power System Load Frequency Control'. IEEE Transactions on Power Systems, Vol. 4, No. 1, February 1989.

[8] Prakash Surya and Sinha Sunil Kumar, 'Performance Evaluation of Hybr -id Intelligent Controllers in Load Frequency Control of Multi Area Interconnected Power Systems'. World Academy of Science, Engineering and Technology, Vol.7 2013 05-26.

[9] Rakhshani E. and Sadeh J., 'Load Frequency Control of Multi-Area Restrutured Power System'. IEEE Power India Conference \& Power on 2008, New Delhi, India, 12-15 October, 978-1-4244-17629/08/\$25.00@2008.

[10] Sinha S. K., Prasad R. and Patel R. N., 'PSO Tuned Combined Optimal Fuzzy Controller for AGC of Two Area Interconnected Power System'. IEEE 978-1-4244-5612-3-09/\$26.00@2009.

[11] S. Sivanagaraju, G. Sreenivasan, 'Power System Operation and Control', PEARSON 2011.

[12] Surya Prakash, S K Sinha, 'Four Area Load Frequency Control of Interconnected Hydro-Thermal Power System by Intelligent PID Control Controller', IEEE 978-1-4673-0455-9/12 2012.

[13] Trivedi Anupam, 'Improved Multi-objective Evolutionary Algorithm for Day Ahead Thermal Generation Scheduling'. IEEE 978-1-4244-78354/11/\$26.00@2011.

[14] Xiuxia Du and Pingkang Li , 'Fuzzy Logic Control Optimal Realization using GA for Multi Area AGC Systems'. IJIT Vol. 12 No.7 2006. 